\title{
ACUTE EFFECT OF WEARING WETSUIT ON 400m PERFORMANCE IN A SWIMMING POOL AND IN A SWIMMING FLUME
}

\author{
Author: ANA GAY PÁRRAGA \\ Tutor: RAÚL ARELLANO COLOMINA \\ Co-tutor: GRACIA LÓPEZ CONTRERAS \\ Department of Physical Education and Sport
}

MÁSTER DE INVESTIGACIÓN EN ACTIVIDAD FÍSICA Y DEPORTE.

FACULTY OF SPORT SCIENCES

UNIVERSIDAD DE GRANADA

CURSO 2015-2016

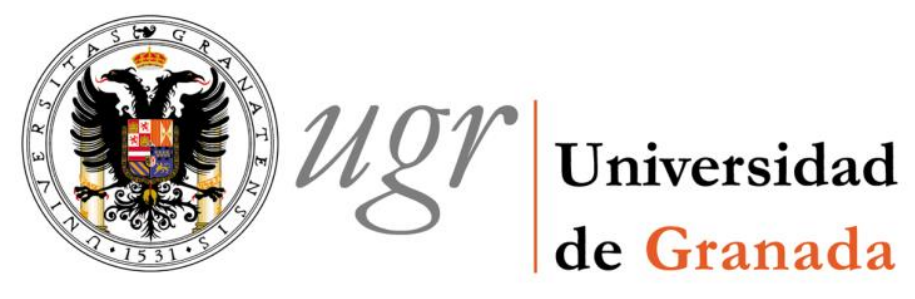




\section{INDEX}

ABSTRACT




\begin{abstract}
The purpose of the present study was to determine the physiological and technical differences between the use of wetsuit compared with the swimsuit in two specific environments the $25 \mathrm{~m}$ swimming pool and a swimming flume. A total of 33 triathletes and open water swimmers (age $26.46 \pm 11.72$ years) participated in the study. The trials were made with and without full body wetsuit randomly and counter balanced for each experimental condition. Two $400 \mathrm{~m}$ trials were randomly performed in a $25 \mathrm{~m}$ pool, one wearing wetsuit and another wearing training swimsuit. Two mores trials performed in the swimming flume with the same duration than the swimming pool trial at the same mean water velocity. The analysis carried out was the repeated measurement ANOVA to determine the differences between four experimental conditions. The results revealed the four experimental conditions had a main effect on velocity $\left(\mathrm{F}_{3,96}=114.02 P<0.001\right)$, stroke frequency $\left(\mathrm{F}_{3,96}=61.37 P<0.001\right)$, blood lactate concentration $\left(\mathrm{F}_{3,96}=19.11\right.$ $P<0.001)$, heart rate $\left(\mathrm{F}_{3,96}=14.31 P=0.059\right)$, ratio of perceived exertion $\left(\mathrm{F}_{3,96}=17.43\right.$ $P<0.01)$, stroke length $\left(\mathrm{F}_{3,96}=214.93 P<0.001\right)$, stroke index $\left(\mathrm{F}_{3,96}=109.54 P<0.001\right)$, and propelling efficiency $\left(\mathrm{F}_{3,96}=41.14 P<0.001\right)$. The use of the wetsuit has a strong influence on $400 \mathrm{~m}$ performance, thanks to small increments of stroke frequency and stroke length, confirmed by the changes in the stroke index. All the variables studied physiological and technical are modified by the use of swimming flume at similar velocities than swimming pool.
\end{abstract}

Keywords: wetsuit, swimming flume, propelling efficiency, triathlon, open water.

\title{
RESUMEN
}

El objetivo del presente estudio fue determinar las diferencias fisiológicas y técnicas entre el uso del neopreno y el bañador convencional en dos condiciones, en piscina de 25 metros y en piscina contracorriente. Un total de 33 triatletas y nadadores de aguas abiertas participaron en el estudio (edad 26.46 \pm 11.72 ). Los ensayos se realizaron con neopreno completo y con bañador convencional de forma aleatoria y contrabalanceada para cada condición experimental. Dos pruebas de $400 \mathrm{~m}$ fueron desarrolladas aleatoriamente, una con neopreno y otra con bañador convencional. Dos pruebas más se realizaron en la piscina contracorriente con la misma duración que las pruebas de la piscina de $25 \mathrm{~m}$ y a la misma velocidad promedio. El análisis estadístico realizado fue ANOVA de medidas repetidas. Los resultados mostraron que las cuatro condiciones experimentales tienen un efecto significativo en velocidad $\left(\mathrm{F}_{3,96}=114.02 \quad P<0.001\right)$, frecuencia de ciclo $\left(\mathrm{F}_{3,96}=61.37 P<0.001\right)$, concentración de lactato en sangre $\left(\mathrm{F}_{3,96}=\right.$ $19.11 P<0.001)$, frecuencia cardíaca $\left(\mathrm{F}_{3,96}=14.31 P=0.059\right)$, ratio de esfuerzo percibido $\left(\mathrm{F}_{3,96}=17.43 P<0.01\right)$, longitud de ciclo $\left(\mathrm{F}_{3,96}=214.93 P<0.001\right)$, índice de ciclo $\left(\mathrm{F}_{3,96}\right.$ $=109.54 P<0.001)$, y eficiencia propulsiva $\left(\mathrm{F}_{3,96}=41.14 P<0.001\right)$. El uso del neopreno tiene una fuerte influencia en el rendimiento en $400 \mathrm{~m}$, gracias a los pequeños incrementos en frecuencia de ciclo y longitud de ciclo, confirmados por los cambios en el índice de ciclo. Todas las variables fisiológicas y técnicas estudiadas fueron 
modificadas por el uso de la piscina contracorriente a similares velocidades que en la piscina de $25 \mathrm{~m}$.

Palabras Clave: neopreno, piscina contracorriente, eficiencia propulsiva, triatlón, aguas abiertas. 


\section{INTRODUCTION}

In triathlon and open water swimming sports the regulations allows taking part in competitions using the wetsuit (neoprene) in determinates environmental conditions or after certain age. Its use is justified to prevent hypothermia (Parsons \& Day, 1986) while its use in normal temperature conditions as $25.6^{\circ}$ Celsius, did not expose the swimmer to any risk of hyperthermia (Todd A Trappe et al., 1995).

The first studies about wetsuit effect were made to clarify the improvement in performance according to the increase of buoyance which is related to the reduction in body drag (De Lucas, Balikian, Neiva, Greco, \& Denadai, 2000; H. M. Toussaint et al., 1989) (Chatard \& Millet, 1996; Chatard, Senegas, Selles, Dreanot, \& Geyssant, 1995; L. Cordain \& Kopriva, 1991). Individuals with high density will benefit more wearing wetsuit.

Some studies tried to demonstrate than the body drag reduction will improve the swimming performance wearing wetsuit. A reduction about $5 \%$ and $3 \%$ in $400 \mathrm{~m}$ and $1500 \mathrm{~m}$ respectively was measured by (L. Cordain \& Kopriva, 1991). For triathletes the improvement in $400 \mathrm{~m}$ trials was a $6 \%(P<0.001)$ but not significant differences for swimmers were found (Chatard et al., 1995). However, swimmers were faster that triathletes with and without wetsuit. Parsons \& Day (1986) found a 7\% of improvement in the distance covered over a 30 min swim with wetsuit. The improvement in the time when wearing a wetsuit in the $1500 \mathrm{~m}$ trial was $3.7 \%$ (De Lucas et al., 2000).

Using a swimsuit, stroke frequency (SF), maximum oxygen consumption $\left(\mathrm{VO}_{2 \max }\right.$ and blood lactate concentration (BLa) were higher and the passive drag was lower for swimmers in comparison with triathletes. In contrast, with wetsuit were not statistically differences for both groups. Although, those variables were lower for swimmers with wetsuit. Also triathletes had a significantly higher SF $(P<0.01)$ (Chatard et al., 1995). De Lucas et al. (2000) found statistically significant differences between swimsuit and wetsuit in BLa $(P<0.05)$ during 30 minutes swim.

Therefore some authors have been studying the performance consequences with different types of wetsuit (Hue, Benavente, \& Chollet, 2003; Hutteau, Beitucci, \& Lodini, 2007; Nicolaou, Kozusko, \& Bishop, 2001; Perrier \& Monteil, 2001; T. A. Trappe, Pease, Trappe, Troup, \& Burke, 1996).

Perrier \& Monteil (2004) showed differences in SF, which were increasing progressive during a $1500 \mathrm{~m}$ swim, together with an increase in stroke length (SL) from the first $100 \mathrm{~m}$ to the last $100 \mathrm{~m}$ of the 1500 swim. As a result, the stroke index (SI) was significantly lower at the end of the trial. To conclude, the wetsuit increased the buoyance, decrease frontal resistance and, as a result, swimming velocity increase due to an increase of SL in comparison with swimsuit (Chatard et al., 1995; L. Cordain \& 
Kopriva, 1991; Parsons \& Day, 1986; Perrier \& Monteil, 2004; H. M. Toussaint et al., 1989).

Recently an author studied the implication in the velocity cause by the use of wetsuit in two open water competitions (Ulsamer, Rust, Rosemann, Lepers, \& Knechtle, 2014). Their results suggest that wearing a wetsuit had a positive influence on swimming speed for women and men but the benefit of the use of wetsuits seemed to depend on additional factors (i.e. race distance). Women seemed to benefit more from wearing wetsuits than men in longer open-water ultra-distance swimming races (their reduction in time was higher with wetsuit than for men).

A way to replicate the continuous swimming (without turns), that characterizes the long distance events, is to use a swimming flume.

Trappe et al., (1996) analyzed the physiological responses in a swimming flume with competitive swimmers. In this study, the wetsuit were full, long (left the arm exposed) and short (left the arm and lower legs exposed). The participants performed four trials of $5 \mathrm{~min}$ duration in the swimming flume in four different velocities $(0.9,1.5,1.18,1.31$ $\left.\mathrm{m} \cdot \mathrm{sec}^{-1}\right)$. The oxygen uptake $\left(\mathrm{VO}_{2}\right)$ and the minute ventilation were slower in the all three wetsuit conditions compared with swimsuit at any velocity. The heart rate (HR) and the ratio of perceived exertion (RPE) were higher when the velocity was increasing. Nonetheless, the significant differences in heart rate and RPE between swimsuit and the three wetsuits appeared with the highest velocity $\left(1.31 \mathrm{~m} \cdot \mathrm{sec}^{-1}\right)$.

More recently, a similar study but using a complete wetsuit with triathletes was developed in the swimming flume (Tomikawa, Shimoyama, \& Nomura, 2008). No significant differences were found in $\mathrm{VO}_{2}$ and BLa between a wetsuit and a swimsuit, but the velocity was $5.4 \%$ higher $(P<0.01)$ when swimming in the wetsuit condition than in the swimsuit condition. The wetsuit in $\mathrm{VO}_{2}$ was beneficial in $60 \%$ of velocity but not in $80 \%$ of the maximal $\mathrm{VO}_{2 \max }$. There were not differences in BLa either RPE with and without wetsuit in both submaximal swims.

Contrary to Perrier \& Monteil (2004), Hutteau et al., (2007) and the hypothesis in the study of Tomikawa at al., (2008), they didn't find differences in SL but the SF increased with wetsuit. Those results concluded the used of wetsuit are associated with enhancement in performance.

One year later, the same author used also the swimming flume to determinate the differences between a $400 \mathrm{~m}$ swim and 50m swim due to the importance to sprint for triathletes together with endurance condition (Tomikawa \& Nomura, 2009). They determined the active drag, its coefficient and mechanical power output (POmax) by the velocity of the sprint swim performance. The results showed that the relationship between velocity in sprint and POmax was higher in the wetsuit condition than the swimsuit condition, as a consequence at the same velocity, a reduction in active drag occurred when wearing a wetsuit (Tomikawa \& Nomura, 2009). Finally, in contrast to their previous study, Tomikawa \& Nomura (2009) found differences in BLa, being 
significantly higher with wetsuit $(P<0.01)$, and also they found higher SF and SL in wetsuit condition $(P<0.01)$ in $400 \mathrm{~m}$ trial. Further, the velocity reached with wetsuit was $6.9 \%$ higher than without, similarly to the $6 \%$ that found Chatard et al., (1995). In the sprint trial, the velocity also increased by $4.3 \%$.

Propelling efficiency $(\mathrm{Pe})$ was defined as the ratio of the useful power (power to overcome drag) to the total power output (Hubb M Toussaint et al., 1988). These authors applied the M.A.D. system (Measurement of Active Drag) to calculate Pe, after obtaining the Active Drag stroke by stroke. Pe was higher for competitive swimmers than for triathletes $(61 \pm 6 \%$ versus $44 \pm 3 \%$ respectively). SL was also significantly greater for swimmers $(1.23$ versus $0.92 \mathrm{~m})$ while the SF was similar, because the triathletes used more energy to move masses of water than competitive swimmers (45 versus 32 watt respectively) (H. M. Toussaint, 1990).

A simplified model was proposed (Martin, Yeater, \& White, 1981) and subsequently adapted showed that Pe depends on the ratio between the swimming speed and the SF $(\mathrm{Hz})$ and the term $l$ which is average shoulder to the hand distance (Zamparo, Pendergast, Mollendorf, Termin, \& Minetti, 2005) [see details of the calculation procedure in the equation 4 of the methods part].

Open water swimming with or without wetsuit seems more properly replicated in a swimming flume, where the turn effect is not accounted. An accurate measurement of the wetsuit effect in both conditions (swimming pool and swimming flume) seems appropriate to develop more specific protocols to open water swimmers. The contradictory results found in some studies related with the wetsuit effect on swimming performance plus the lack of the studies where multiple physiological and biomechanical variables were simultaneously measured in swimming pool and swimming flume motivated us to initiate this project.

The aim of the present study was to determine the physiological and technical differences between the use of wetsuit compared with the swimsuit in two specific environments the $25 \mathrm{~m}$ swimming pool and a swimming flume.

We hypothesized the use of wetsuit produces an enhancement in performance swimming in a $25 \mathrm{~m}$ pool versus the swimsuit and even more differences in the swimming flume where the turn effect is not accounted. 


\section{MATERIAL AND METHODS}

\section{Participants}

A total of 33 triathletes and open water swimmers participated in the study. All of them had been informed about the study and they consented to participate voluntarily. In the case of minors, the tutors consented of their participation. All participants practiced and competed in triathlon and/or open water swimming and they were-used to wear a full body wetsuit. In all the cases, the wetsuit covered the trunk, the legs until the ankles and the arms until the wrists, but not the head. The trials were made with and without full body wetsuit randomly and counter balanced for each experimental condition.

The University of Granada's Ethics Committee of Human Research approved the development of this study.

The general characteristics of the participants are shown in table 1.

\section{Procedures}

The study has a cross sectional design and it is a quasi-experimental study.

Two $400 \mathrm{~m}$ trials were randomly performed in a $25 \mathrm{~m}$ pool, one wearing wetsuit and another wearing training swimsuit. Each participant started in the water. Afterwards, two trials were randomly assessed in the swimming flume (Endless Pool Elite Techno Jet Swim 7.5 HP, Aston PA, EE.UU.) that provided a $2.4 \times 4.7 \mathrm{~m}$ area of flow that varied in depth from $0.6 \mathrm{~m}$ at the sides to $1.2 \mathrm{~m}$ in the center of the channel. Flow speed in the flume was measured at a depth of $0.30 \mathrm{~cm}$ below the water surface (T0.03 mIsj1) using an FP101 flow probe (Global Water, Gold River, CA) (McLean, Palmer, Ice, Truijens, \& Smith, 2010). The channel's velocity range was 0.4 to $1.9 \mathrm{~m} \cdot \mathrm{s}^{-1}$ and the water temperature was set at $27^{\circ}$ Celsius. They swam in the same conditions (with and without wetsuit). The swimming flume trials had the same duration than the swimming pool trial at the same mean water velocity.

All of the trials were performed at least with 48 hours of rest between them and the participants were informed abstain to take stimulant or caffeinated beverages from the night before the trials and not to practice exhausting exercise in these 48 hours.

Water temperature was around $27^{\circ}$ Celsius in both pools.

There were not risks for health because the trials were submaximal in all four conditions. 
Table 1. Main characteristics of the participants in the study (mean \pm SD). Total mean values, grouped by sex.

\begin{tabular}{|c|c|c|c|}
\hline & Total & Male & Female \\
\hline $\mathbf{N}$ & 33 & 20 & 13 \\
\hline Age (years) & $26.46 \pm 11.72$ & $26.3 \pm 12.8$ & $26.69 \pm 10.34$ \\
\hline Height (cm) & $171.64 \pm 8.69$ & $175.86 \pm 7.47$ & $165.15 \pm 6.12$ \\
\hline Body mass (kg) & $67.13 \pm 11.44$ & $72.78 \pm 9.98$ & $58.45 \pm 7.55$ \\
\hline BMI $\left(\mathrm{kg} / \mathrm{m}^{2}\right)$ & $22.62 \pm 2.11$ & $23.44 \pm 1.87$ & $21.36 \pm 1.87$ \\
\hline Body fat (kg) & $9.71 \pm 2.77$ & $10.20 \pm 2.62$ & $8.97 \pm 2.93$ \\
\hline Body fat (\%) & $14.36 \pm 2.79$ & $13.92 \pm 2.46$ & $15.04 \pm 3.22$ \\
\hline Arm Span (cm) & $176.79 \pm 10.10$ & $182.09 \pm 8.52$ & $168.63 \pm 6.17$ \\
\hline Hand surface $\left(\mathrm{cm}^{2}\right)$ & $112.65 \pm 16.25$ & $121.58 \pm 14.06$ & $98.91 \pm 7.32$ \\
\hline Foot surface $\left(\mathrm{cm}^{2}\right)$ & $132.88 \pm 24.16$ & $143.48 \pm 24.83$ & $116.56 \pm 10.25$ \\
\hline $\begin{array}{l}\text { Total time on } 400 \mathrm{~m} \\
\text { freestyle (s) }\end{array}$ & $348.13 \pm 46.46$ & $345.04 \pm 48.17$ & $352.87 \pm 45.19$ \\
\hline Mean velocity $\left(m \cdot s^{-1}\right)$ & $1.17 \pm 0.16$ & $1.18 \pm 0.17$ & $1.15 \pm 0.14$ \\
\hline FINA Points & $284.4 \pm 115.71$ & $261.92 \pm 116.28$ & $318.98 \pm 110.25$ \\
\hline
\end{tabular}




\section{Protocol}

Several days before the experiment began, the participants swam during five minutes with and without wetsuit in the swimming flume to familiarize with it. When they finished, they practiced with the RPE Category ratio 10 (CR10) Borg Scale (Borg, 1998).

During the experimental trials, the protocol followed was: 1) warm up consisting of $200 \mathrm{~m}$ different styles, 4 repetitions of 50m progressive, $100 \mathrm{~m}$ easy, 4 repetition of $25 \mathrm{~m}$ doing half sprint, half slow and 100m warm down. 2) The trial started 5 minutes after finished the warm up, time while the material was prepared to the participant and time enough to allow sufficient recovery (Tomikawa et al., 2008). 3) Before the trial in the swimming flume, they performed a low intensity one-minute effort to adapt to it. 4) After that, they rested during one minute and they started the trial immediately. The heart rate was measured during the full trial and, after it, blood lactate concentration (BLa, mmol. $\mathrm{l}^{-1}$ ) was measured three minutes after the trial and the RPE (Borg, 1998).

\section{Material}

Swimming pools.

We use two different swimming pools. The first one was a $25 \mathrm{~m}$ pool which has marks on the floor each five meters.

The second one was a swimming flume (characteristics aforementioned).

\section{Video analysis}

The 400m trials were recorded with a camera Nikon 1J1 (Nikon Corp., Japan) recorded at 60 frames per second to obtain all laps times during the trial. A LED light switched on every time the swimmer touched the timing pad (Alge Timing, Training Pad TP980 Lustenau, Austria).

Furthermore, all the trials (in $25 \mathrm{~m}$ pool and in the swimming flume) were recorded underwater with the same camera Panasonic (50 Hz, Full-HD HX-A500, Osaka, Japan), located perpendicular to the plan of displacement in the center of the swimming pool to analyze technical variables. In the swimming flume, the camera only recorded the right side of the body, while the left side was reflected in a mirror, which was on the bottom of the pool (about 45 degrees).

Reference points were drawn at the shoulders, hips and wrists of the participants to help to analyze the technical variables. As a reference to the video analysis, we situated two calibrated sticks in center of the $25 \mathrm{~m}$ pool with five meter between them. The same system was used in the swimming flume but with one meter between them.

HR was recorded with CardioSwim, (Freelap, Fleurier, Switzerland) and lactate concentration with Lactate Pro2 (Arkray, Amstelveen, The Netherlands). 


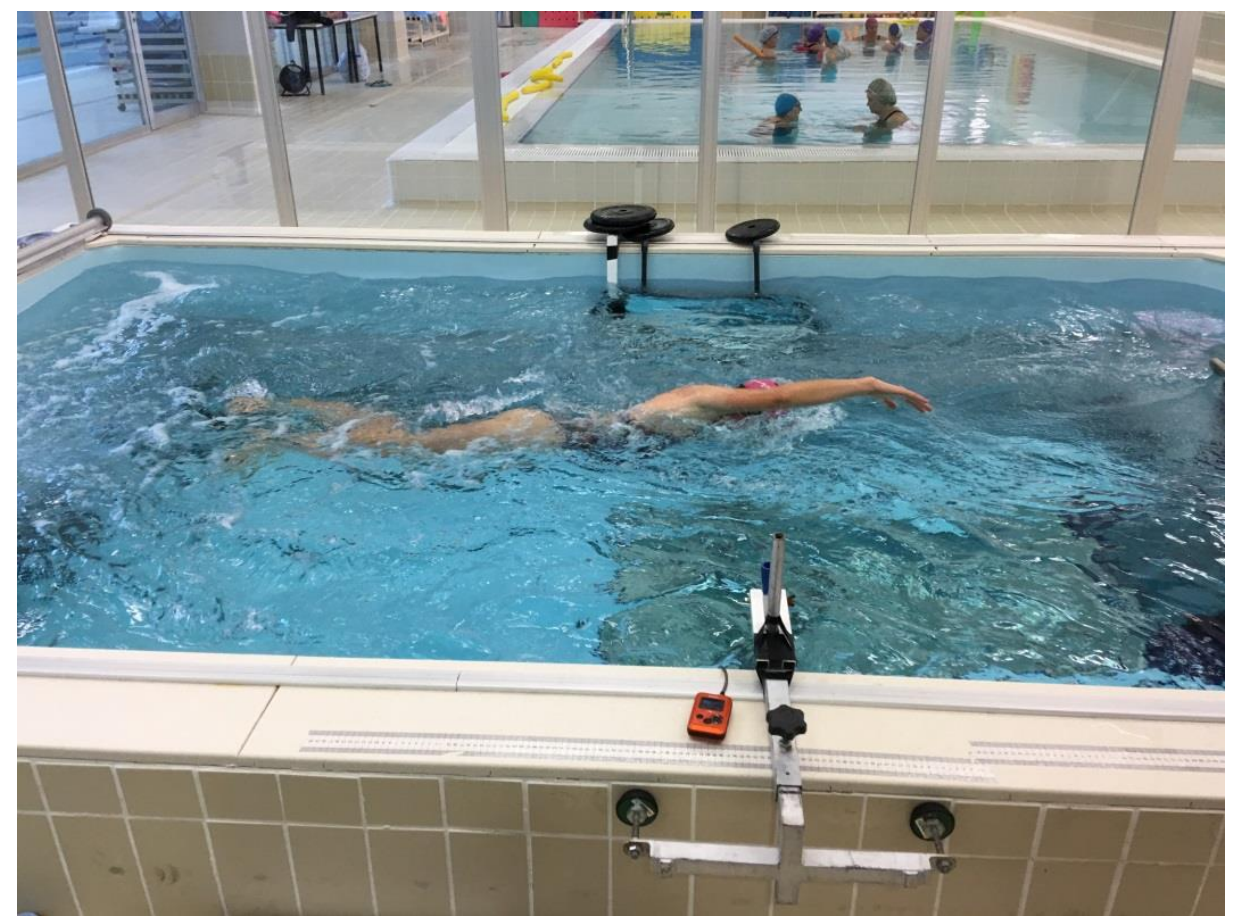

Fig. 1. Swimming flume with camera Panasonic (50 Hz, Full-HD HX-A500, Osaka, Japan), located perpendicular to the plan of displacement in the center of the swimming pool and a mirror situated on the bottom of the pool (about 45 degrees).

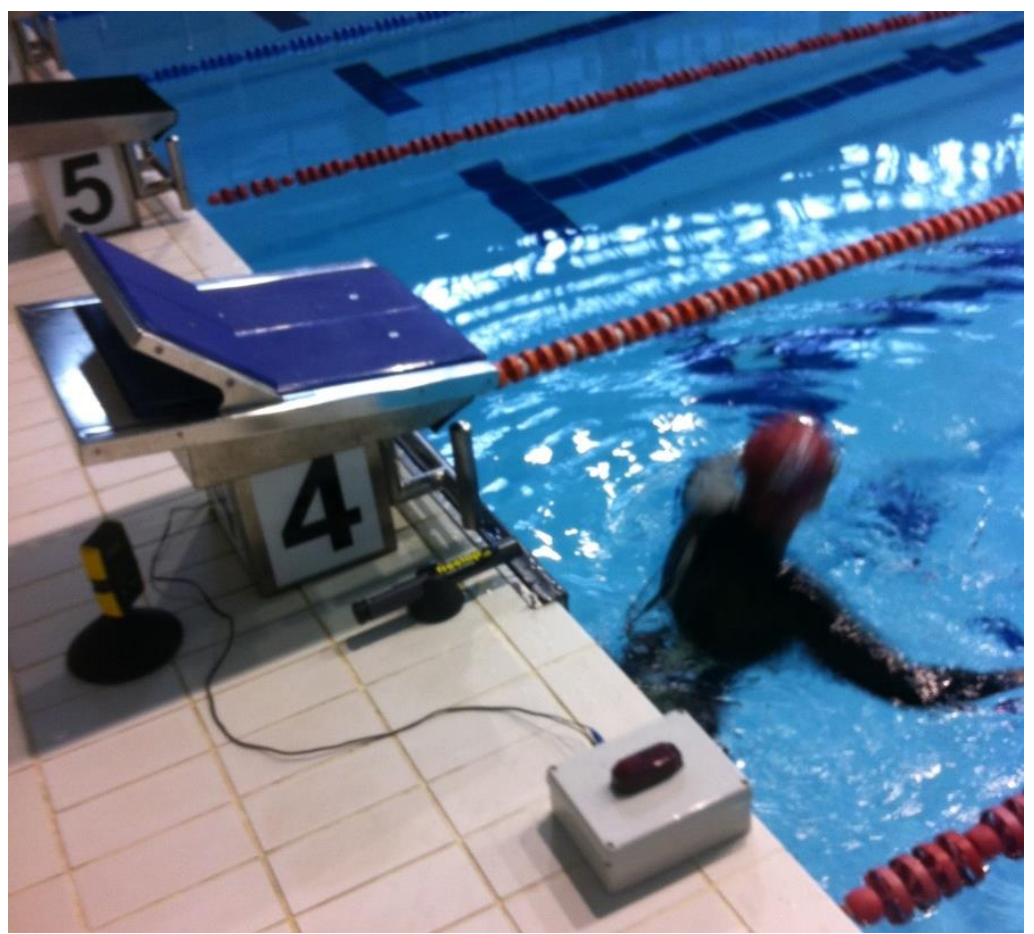

Fig. 2. TX H2O Freelap, Relay Swim Freelap (Fleurier, Switzerland) and a LED light connected on the timing pad (Alge Timing, Training Pad TP980 Lustenau, Austria). 


\section{Variables}

\section{Independent variables}

We manipulated the $400 \mathrm{~m}$ swimming effort defining four conditions or I.V. levels: 1) swimming pool wearing normal swimsuit; 2) swimming pool wearing wetsuit; 3) swimming flume wearing normal swimsuit and; 4) swimming flume wearing wetsuit. The intensity at the swimming flume was adjusted based in the swimming pool performances.

\section{Anthropometric measurements}

It was measured the body weight, body height, arm spam (measured with the swimmers sitting on their knees and arms and fingers fully extended in lateral abduction at a $90^{\circ}$ with the trunk supported on a curb, the distance between the third fingertip was measured whit a meter fixed on that curb), body height in minimum resistance position (MRP), areas of right hand and foot and area of transversal section of the body (ImageJ Launcher, Maryland, USA). Body fat composition was estimated from the skinfold thickness (expressed in $\mathrm{mm}$ ) representing the sum of eight skin areas (biceps, triceps, subscapular, supraspinal, suprailiac, abdominal, quadriceps and gastrocnemius) measured with Amefda Calipers (Slim Guide, Spain), on the right side of the body, including the perimeters of biceps, biceps in a relaxed position, quadriceps and gastrocnemius and the diameters of the wrist, elbow and knee measured with GPM Pachymeter (Sliding Caliper, Zurich, Switzerland). Everything was measured following the method of (De Rose \& Guimaraes, 1980). To calculate the body fat we used the equation of (Faulkner, 1968). Those methods were analyzed using a software (Excel, version 2010) developed by Sanchez C. and Zabala M. (2015).

\section{Heart Rate measurements (HR)}

HR was recorded using Freelap system and analyzed with the software ("Manager" v2.1.13, Fleurier, Switzerland). HR recordings included the trial time before and after dressing their swimsuit or wetsuit plus warming up.

During the 400m trial we used TX H2O Freelap and Relay Swim Freelap (Fleurier, Switzerland) equipment to measure $50 \mathrm{~m}$ splits and to synchronize the swimming displacement with HR. In the swimming flume we used the same systems to determine the heart rate start point and the heart rate end point of the trial.

The continuous HR recordings allowed the measurement of minimal, maximal and average HR, every $50 \mathrm{~m}$ or similar time in all the experimental conditions. For both conditions we analyzed the final hear rate with the average of the ten finals beats.

\section{Post-exercise blood lactate concentration (BLa)}

Three minutes after each trial a blood sample was taken from the third fingertip of the right hand to measure BLa.

It was taken micro-samples only with the purpose to measure BLa. It was taken by the author of this work, not medical personal but as the new ley made by Sub-Directorate 
General of Professional Regulation of the Ministry of Health, Social Services and Equality (Exit Registration Number 13420), in response to the consultation on 10 June 2015 by the Council COLEF (No. 21 Departure Record) said, students with a degree in Sport Sciences can take those kinds of samples.

Ratio of Perceived exertion (RPE)

Directly after the trial, they said the rating of perceived exertion by the CR10 Borg Scale (Borg, 1998). It have been demonstrated the importance of RPE because of the tendency of athletes to change pace during competitive simulations is related both to how they feel momentarily (RPE) and to how much of the event remains (De Koning et al., 2011).

\section{Average velocity}

Swimming velocity $(v)$ was computed in the middle of each $100 \mathrm{~m}$ of the $400 \mathrm{~m}$ trial. It was used:

$$
v=\mathrm{d} \cdot \mathrm{t}^{-1}
$$

Where $v$ is the mean swimming velocity $\left(\mathrm{m} \cdot \mathrm{s}^{-1}\right), \mathrm{d}$ is the distance $(\mathrm{m})$ and $\mathrm{t}$ is the time (s). The mean velocity was adjusted during swimming flume's trials.

A specific database was developed to measure the video time code and to calculate the average velocity between references (Filemaker v14.5, California, United States) in the $25 \mathrm{~m}$ lap corresponding to 50, 200 and $400 \mathrm{~m}$.

Stroke Frequency (SF), Stroke Length (SL) and Stroke Index (SI)

A similar procedure than $v$ was applied to obtain the two cycles times to calculate the stroke frequency $\left(\mathrm{SF}\right.$, cycles. $\mathrm{min}^{-1}$ ) stroke length and stroke index each $25 \mathrm{~m}$ lap corresponding to 50, 200 and 400m In the swimming flume, we measured three cycles to analyze the SF in the time of swimming that corresponds to those splits..

SL was computed as (Craig \& Pendergast, 1979):

$$
\mathrm{SL}=v \cdot \mathrm{SF}^{-1}
$$

Where SL represents stroke length (in $\mathrm{m}), v$ represents the mean velocity $\left(\mathrm{m} \cdot \mathrm{s}^{-1}\right.$ ) and SF represents the stroke frequency $(\mathrm{Hz})$.

SI is strongly associated with a low Energy Cost (C) (Costill et al., 1985). SI can also be used as overall swimming efficiency estimation (Barbosa et al., 2010). SI is computed as:

$$
\mathrm{SI}=\mathrm{SL} \cdot v
$$


Where SI represents stroke index $\left(\mathrm{m}^{2} \cdot \mathrm{s}^{-1}\right)$, SL represents stroke length $(\mathrm{m})$ and $v$ is the mean swimming velocity $\left(\mathrm{m} \cdot \mathrm{s}^{-1}\right)$.

\section{Propelling Efficiency $(\mathrm{Pe})$}

The propelling efficiency was estimated as suggested by Zamparo, et al., (2005):

$$
\eta_{p}=\left[\left(\frac{v \cdot 0.9}{2 \pi \cdot S F \cdot l}\right) \cdot \frac{2}{\pi}\right] \cdot 100
$$

Where $\boldsymbol{\eta}_{\boldsymbol{p}}$ is the propelling efficiency (in $\%$ ) $v$ is the average forward speed of the swimmer $\left(\mathrm{m} \cdot \mathrm{s}^{-1}\right)$, SF is the stroke frequency $(\mathrm{Hz})$ an $l$ is the distance between the shoulder and wrist during the insweep $(\mathrm{m})$ measured using calibrated planar video graphic techniques in the swimming pool and in the swimming flume.

\section{International Swimming Federation points (FINA points)}

The both $400 \mathrm{~m}$ performance with and without wetsuit were evaluated using an international point score system recognized by the International Swimming Federation (FINA), which permits the comparison of performance by male and female swimmers in any of the different swimming events (freestyle, backstroke, breaststroke, butterfly, and individual medley). This system links a point score to each swim performance scaled to 1000 points (a score of 1000 points is equal to the mean of the eight fastest times in the history for that event) (Jean-St-Michel E. et al., 2011).

The equation to calculate the FINA points were:

$$
\mathrm{P}=1000 \cdot(\mathrm{B} / \mathrm{T})^{3}
$$

Where $\mathrm{P}$ was the points, with the swim time (T) and the base time (B). The base time is 212,25s for men and 234,52s for women according to the (FINA Points Scoring, Short Course, 2015).

\section{Statistical procedures}

Descriptive statistic was used to show the sample characteristics. Descriptive statistics of the data were expressed as the mean \pm SD and the $95 \%$ confidence interval (CI).

The assumptions of normally distributed samples were verified for all dependent variables by Kolmogorow-Smirnov trials (for big datasets). To verify sphericity the Mauchly trial was used in the case of ANOVA of repeated measurements.

The analysis carried out was the repeated measurement ANOVA to determine the acute differences between four experimental conditions, with and without wetsuit and the results in the $25 \mathrm{~m}$ pool and in the swimming flume. In the analysis, the 0.05 level of significance was adopted and paired comparisons were used in conjunction with Holm's Bonferroni method to control for type 1 errors. 
It was made a T-Student to correlated samples to apply for two variables which had only two experimental conditions (total time in $400 \mathrm{~m}$ and FINA points $25 \mathrm{~m}$ pool with swimsuit and with wetsuit).

The relationships between anthropometric, physiological and technique variables were modeled with bivariate Pearson correlation analysis.

The IBM SPSS Statistics (Version 20, IBM SPSS, Chicago, IL, USA) was in all the analysis. 


\section{RESULTS}

Basic characteristics of the participants are summarized in table 1, differentiating between male and female. Differences in performance and anthropometric variables between men and women can be considered standard.

Bivariate correlation analysis was made to know relationship between anthropometric and technical variables and between all variables in general (figures 5 and 6, plus table 5 in Annex IV). Kolmogorow-Smirnov test showed the normality of the sample for the majority of the variables, supporting the adequacy of the parametric model one-way repeated-measures ANOVA.

Results obtained on each dependent variable under every experimental condition are shown in Tables 2 and 3, including mean, SD and CI 95\%. The figures included in figure $7 \mathrm{a}$ and figure $7 \mathrm{~b}$ shows the mean and CI (95\%) to visually differentiate the effect of each level of the experimental conditions. Additionally, figure 10 and table 4 (Annex III-IV) shows the technical variables during three different moments of the effort: first 50, 200 and 400m.

A T-test for correlated samples was performed to analyze the positive effect of wearing wetsuit in the $400 \mathrm{~m}$ swimming performance $\left(\mathrm{T}_{32}=91.74 P<0.001\right)$. The time was reduced thanks to the wetsuit about 20s. These values defined the mean swimming velocity applied in the swimming flume.

The one-way repeated measures ANOVA analyses revealed that the four experimental conditions had a main effect on $v\left(\mathrm{~F}_{3,96}=114.02 P<0.001\right)$, SF $\left(\mathrm{F}_{3,96}=61.37 P<0.001\right)$, $\operatorname{BLa}\left(\mathrm{F}_{3,96}=19.11 P<0.001\right), \mathrm{HR}\left(\mathrm{F}_{3,96}=14.31 P=0.059\right), \operatorname{RPE}\left(\mathrm{F}_{3,96}=17.43 P<0.01\right)$, SL $\left(\mathrm{F}_{3,96}=214.93 P<0.001\right)$, SI $\left(\mathrm{F}_{3,96}=109.54 P<0.001\right)$, and $\mathrm{Pe}\left(\mathrm{F}_{3,96}=41.14\right.$ $P<0.001)$.

Observing the results in the figures $7 \mathrm{a}$ and $7 \mathrm{~b}$, and their significant post hoc differences, SF, HR, BLa and RPE show higher values in the swimming pool compared with the swimming flume, while SL, SI and Pe show lower values.

SL, SI and $v$ were the variables that increased significantly (see figure $7 \mathrm{~b}$ ) thanks to wearing wetsuit. The detailed interaction between technical variables in the four experimental conditions can be observed at the figure 8. Considering the possible effect of the effort duration some variables were measured during the first $50 \mathrm{~m}, 200 \mathrm{~m}$ and 400m. The figure 10 (Annex III) shows the results with an increase of the HR during the effort in all the conditions. Similar values of $v$ and SR were found during all the experimental conditions [ $\boldsymbol{v}$ was the variable controlled experimentally to make similar experimental conditions between swimming pool and swimming flume]. 


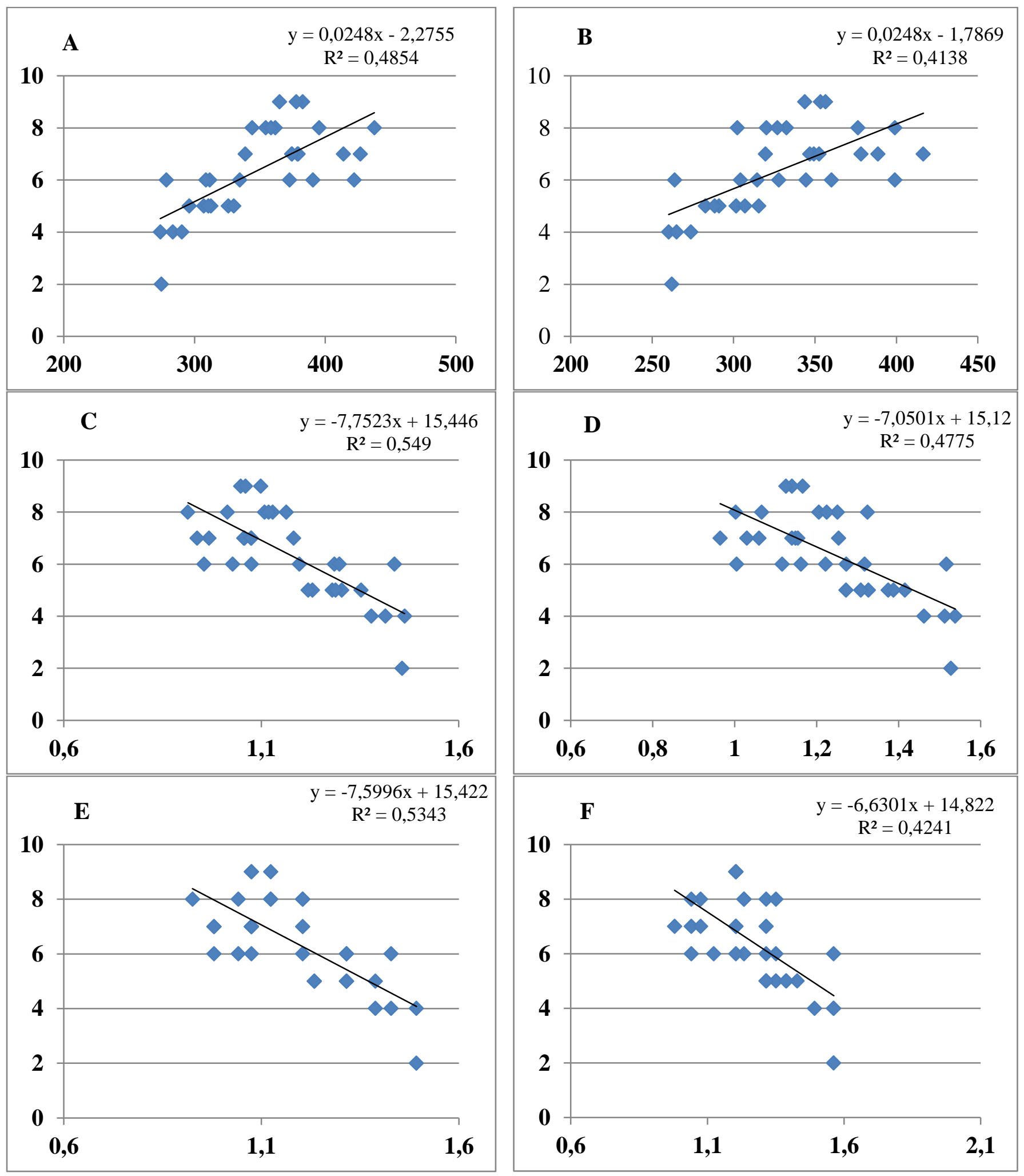

Fig. 5. Correlation between RPE in experimental condition 4 (flume with wetsuit) with total time in $400 \mathrm{~m}$ swimsuit (A), with total time in $400 \mathrm{~m}$ wetsuit (B), with mean velocity in $25 \mathrm{~m}$ pool swimsuit (C), with mean velocity in $25 \mathrm{~m}$ pool wetsuit (D), with mean velocity in flume with swimsuit (E) and with mean velocity in flume wetsuit $(\mathrm{F})$. 


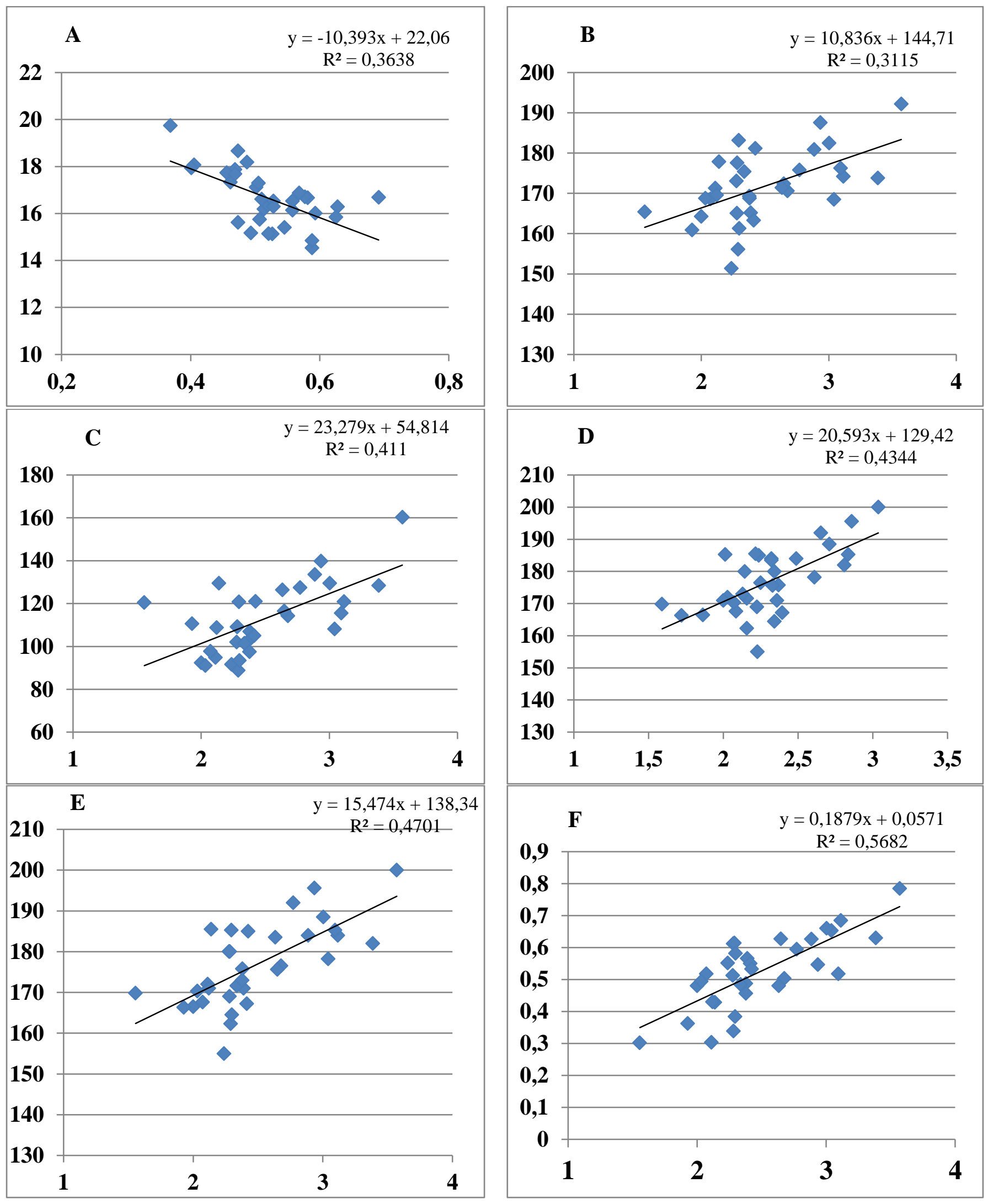

Fig. 6. Correlation between longitudinal perimeter hand and stroke rate in flume with wetsuit (A), height with stroke length in flume with wetsuit (B), hand surface with stroke length in in flume with wetsuit (C), arm spam with stroke length in flume with swimsuit (D), arm spam with stroke length in flume with wetsuit (E) and propelling efficiency in flume wetsuit condition with stroke length in flume with wetsuit $(\mathrm{F})$. 
Table 2. Physiological and subjective characteristics of the participants in the study (mean $\pm \mathrm{SD}$ and $95 \%$ C.I.). Total mean values, grouped by experimental condition (EC1: 25m pool with swimsuit; EC2: 25m pool with wetsuit; EC3: flume with swimsuit; EC4: flume with wetsuit)

\begin{tabular}{|c|c|c|c|c|c|c|c|c|}
\hline & \multicolumn{8}{|c|}{ Mean \pm SD and CI $(95 \%)$} \\
\hline & \multicolumn{2}{|c|}{ EC1 } & \multicolumn{2}{|c|}{ EC2 } & \multicolumn{2}{|c|}{ EC3 } & \multicolumn{2}{|c|}{ EC4 } \\
\hline $\mathbf{N}$ & \multicolumn{2}{|r|}{33} & \multicolumn{2}{|r|}{33} & \multicolumn{2}{|c|}{33} & \multicolumn{2}{|r|}{33} \\
\hline $\begin{array}{l}\text { Heart Rate } \\
\text { Final } \\
\left(\text { beats· } \text { min- }^{\mathbf{1}}{ }^{\text {) }}\right.\end{array}$ & $175.80 \pm 13.78$ & $(170.92 ; 180.69)$ & $179.50 \pm 11.96$ & $(175.26 ; 183.74)$ & $167.52 \pm 14.80$ & $(162.27 ; 172.77)$ & $166.76 \pm 15.77$ & $(161.17 ; 172.35)$ \\
\hline $\operatorname{BLa}\left(\mathrm{mmol} \cdot \mathrm{I}^{-1}\right)$ & $8.89 \pm 2.86$ & $(7.877 ; 9.91)$ & $8.05 \pm 2.55$ & $(7.15 ; 8.96)$ & $5.94 \pm 2.99$ & $(4.88 ; 7.00)$ & $5.82 \pm 3.23$ & $(4.67 ; 6.96)$ \\
\hline $\begin{array}{l}\text { RPE (CR10 } \\
\text { Borg) }\end{array}$ & $7.91 \pm 0.84$ & $(7.61 ; 8.21)$ & $7.90 \pm 1.23$ & $(7.47 ; 8.35)$ & $6.36 \pm 1.78$ & $(5.73 ; 7.00)$ & $6.36 \pm 1.66$ & $(5.78 ; 6.95)$ \\
\hline
\end{tabular}


Table 3. Technical variables of the participants in the study (mean \pm SD and 95\% C.I.). Total mean values, grouped by experimental condition (EC1: $25 \mathrm{~m}$ pool with swimsuit; EC2: 25m pool with wetsuit; EC3: flume with swimsuit; EC4: flume with wetsuit)

\begin{tabular}{|c|c|c|c|c|c|c|c|c|}
\hline & \multicolumn{8}{|c|}{ Mean \pm SD and CI $(95 \%)$} \\
\hline & \multicolumn{2}{|c|}{ EC1 } & \multicolumn{2}{|c|}{ EC2 } & \multicolumn{2}{|c|}{ EC3 } & \multicolumn{2}{|c|}{ EC4 } \\
\hline $\mathbf{N}$ & \multicolumn{2}{|c|}{33} & \multicolumn{2}{|c|}{33} & \multicolumn{2}{|c|}{33} & \multicolumn{2}{|c|}{33} \\
\hline $\begin{array}{l}\text { Total time on } 400 \\
\text { m freestyle (s) }\end{array}$ & $348.13 \pm 46.46$ & $(331.65 ; 364.60)$ & $328.05 \pm 42.85$ & $(312.86 ; 343.24)$ & & & & \\
\hline $\begin{array}{l}\text { Mean velocity } \\
\left(\mathbf{m} \cdot \mathbf{s}^{-1}\right)\end{array}$ & $1.17 \pm 0.16$ & $(1.12 ; 1.23)$ & $1.24 \pm 0.16$ & $(1.19 ; 1.30)$ & $1.19 \pm 0.16$ & $(1.14 ; 1.25)$ & $1.28 \pm 0.16$ & $(1.22 ; 1.33)$ \\
\hline $\begin{array}{l}\text { Stroke Frequency } \\
(\mathbf{H z})\end{array}$ & $0.61 \pm 0.07$ & $(0.58 ; 0.64)$ & $0.62 \pm 0.09$ & $(0.59 ; 0.65)$ & $0.52 \pm 0.06$ & $(0.50 ; 0.55)$ & $0.52 \pm 0.07$ & $(0.50 ; 0.55)$ \\
\hline Stroke length (m) & $1.76 \pm 0.2$ & $(1.69 ; 1.84)$ & $1.84 \pm 0.23$ & $(1.76 ; 1.92)$ & $2.30 \pm 0.32$ & $(2.19 ; 2.42)$ & $2.48 \pm 0.45$ & $(2.33 ; 2.63)$ \\
\hline $\begin{array}{l}\text { Stroke Index } \\
\left(\mathbf{m}^{2} \cdot \mathbf{s}^{-1}\right)\end{array}$ & $1.90 \pm 0.4$ & $(1.76 ; 2.04)$ & $2.10 \pm 0.47$ & $(1.94 ; 2.27)$ & $2.78 \pm 0.67$ & $(2.53 ; 3.01)$ & $3.22 \pm 0.91$ & $(2.89 ; 3.54)$ \\
\hline $\begin{array}{l}\text { Propelling } \\
\text { Efficiency (\%) }\end{array}$ & $40,63 \pm 6,25$ & $(38,41 ; 42,84)$ & $40,00 \pm 7,51$ & $(37,34 ; 42,67)$ & $51,56 \pm 11,30$ & $(47,56 ; 55,57)$ & $52,41 \pm 11,16$ & $(48,45 ; 56,37)$ \\
\hline FINA Points & $284.4 \pm 115.71$ & $(243.37 ; 325.43)$ & $335.56 \pm 126.74$ & $(290.62 ; 380.50)$ & & & & \\
\hline
\end{tabular}




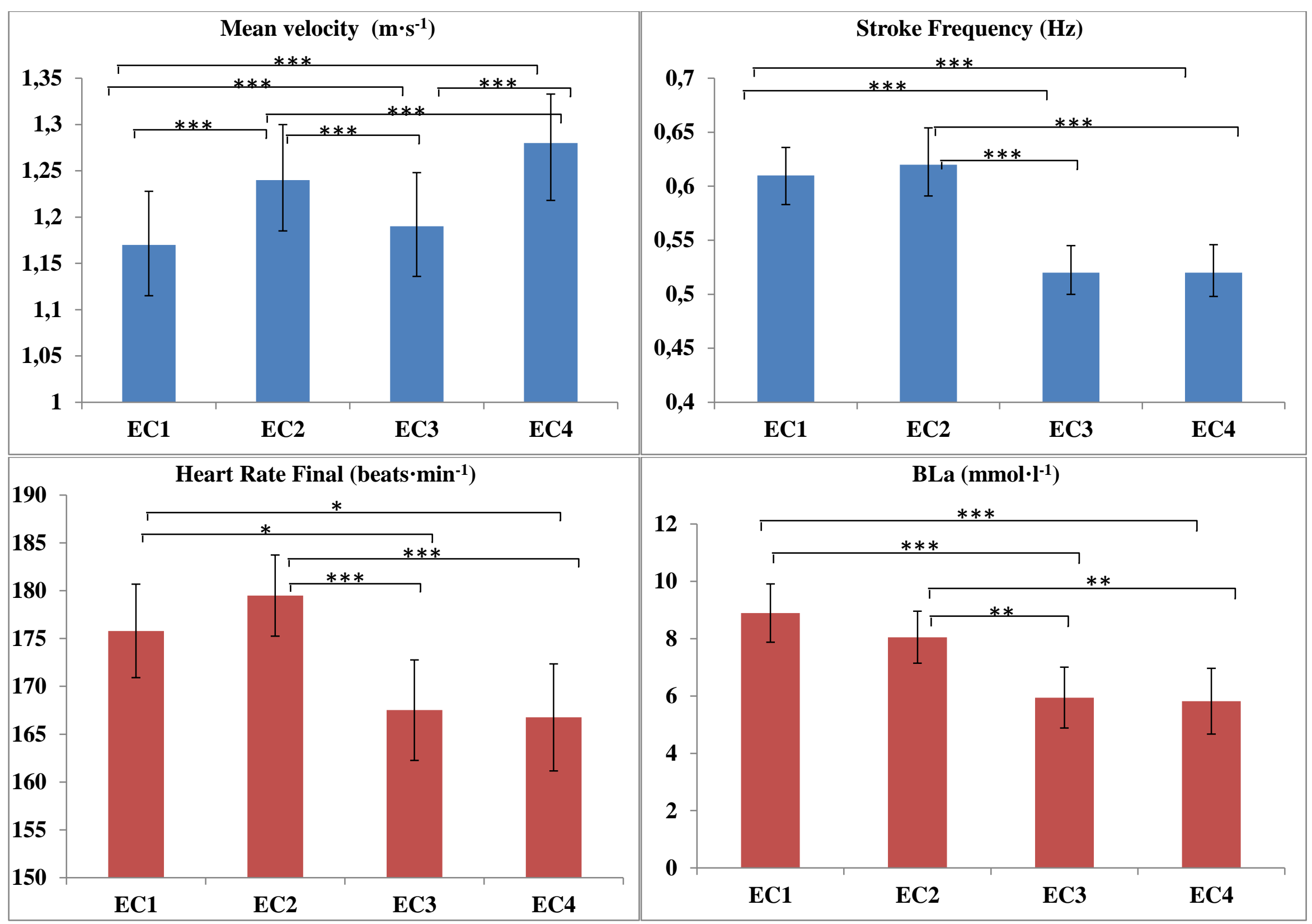

Fig. 7a. Differences in technical variables in four experimental conditions (EC1: 25m pool with swimsuit; EC2: 25m pool with wetsuit; EC3: flume with swimsuit; EC4: flume with wetsuit). The error bars errors bars represent the coefficient interval of $95 \%$. *** $P<0.001 ; * * P<0.01 ; * P<0.05$. 


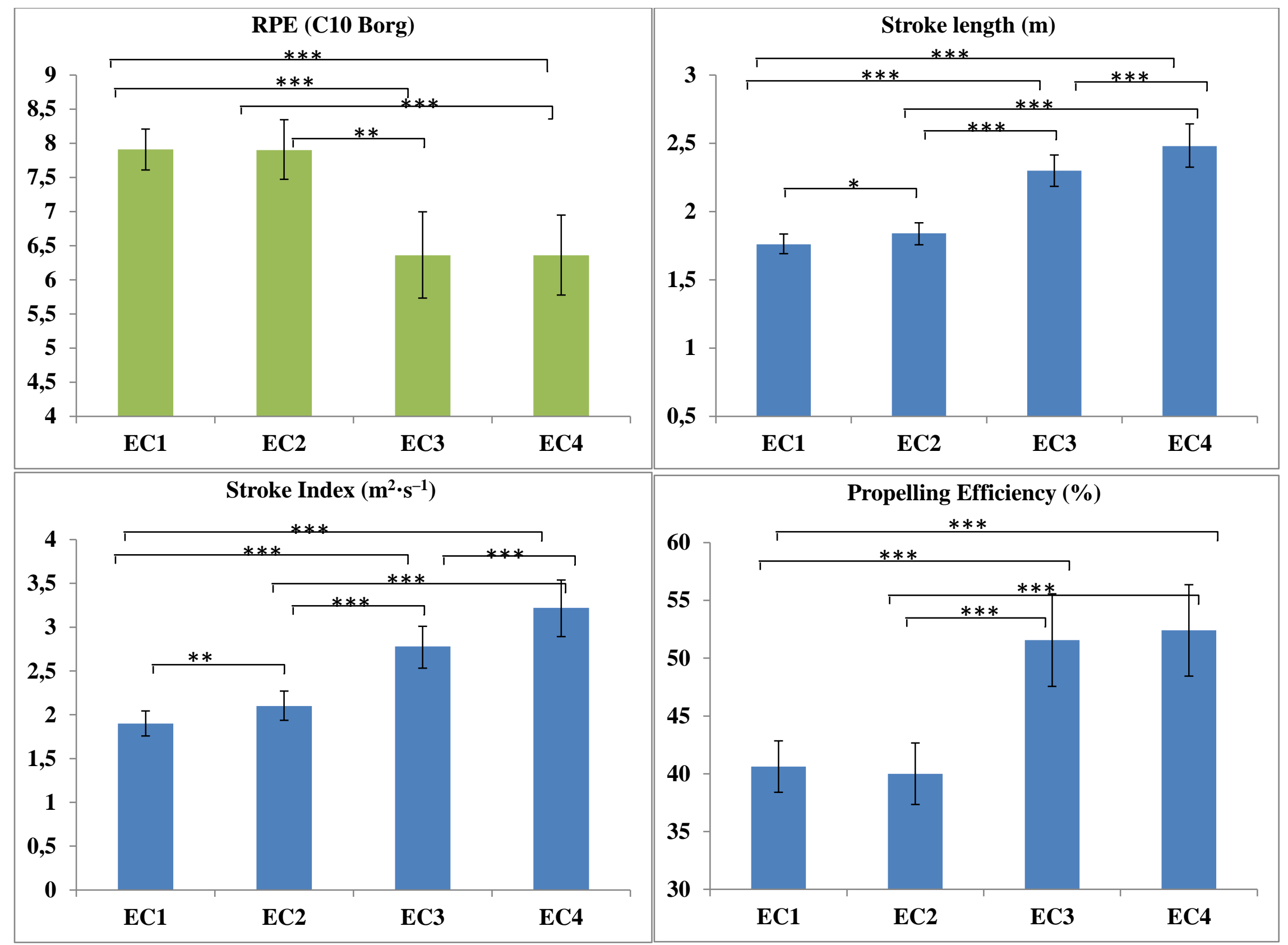

Fig. 7b. Differences in technical variables in four experimental conditions (EC1: 25m pool with swimsuit; EC2: 25m pool with wetsuit; EC3: flume with swimsuit; EC4: flume with wetsuit). The error bars errors bars represent the coefficient interval of $95 \%$. *** $P<0.001 ; * * P<0.01 ; * P<0.05$. 


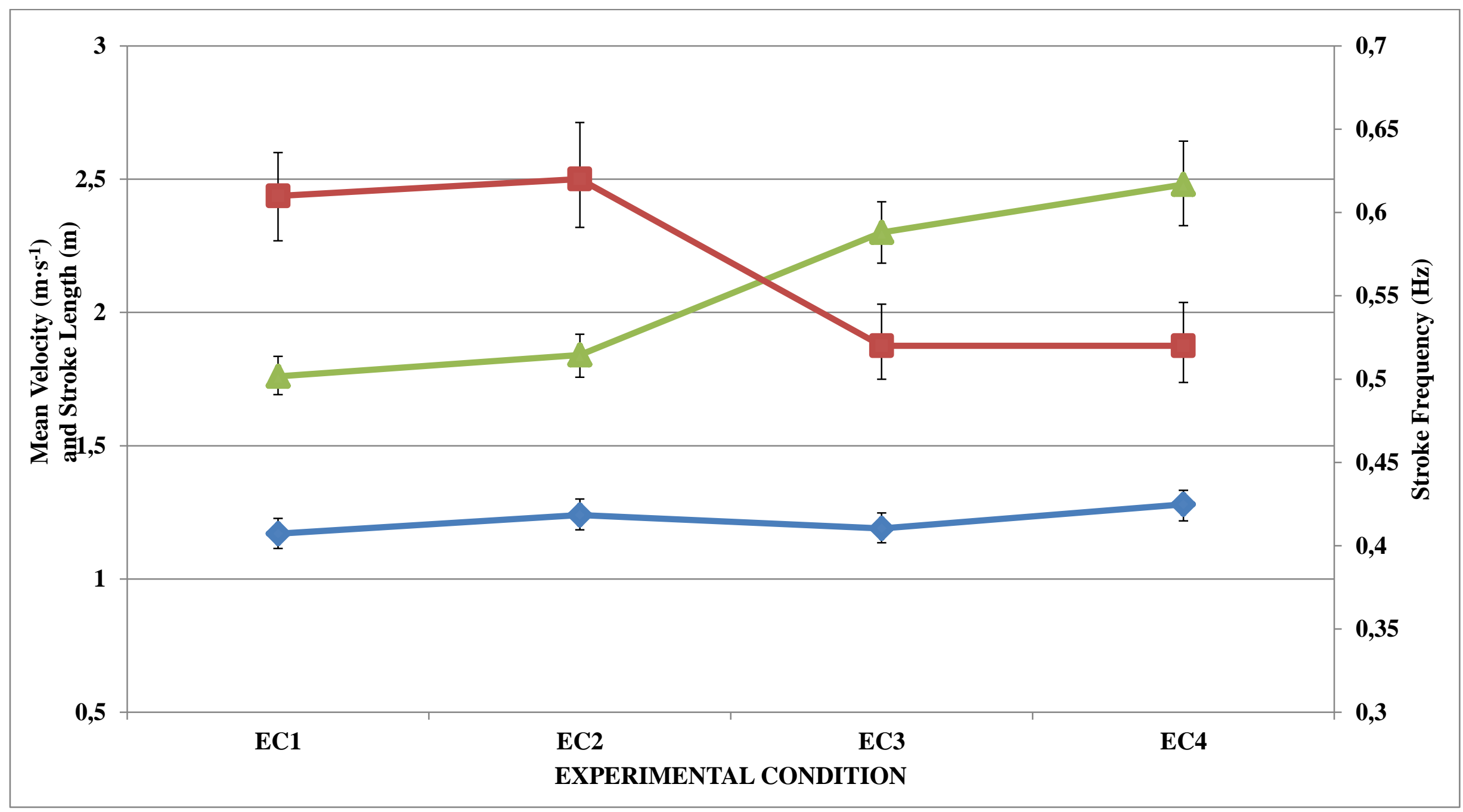

Fig. 8. Relationship between mean velocity (blue line), stroke length (green line) and stroke rate (red line) in four experimental conditions (EC1: $25 \mathrm{~m}$ pool with swimsuit; EC2: 25m pool with wetsuit; EC3: flume with swimsuit; EC4: flume with wetsuit). The error bars errors bars represent the coefficient interval of 95\%. 


\section{DISCUSSION}

The aim of the present study was to determine the physiological and technical differences between the use of wetsuit compared with the swimsuit in two specific environments the $25 \mathrm{~m}$ swimming pool and a swimming flume. The results of the study confirmed that the time when using wetsuit was lower that with swimsuit in the $400 \mathrm{~m}$ crawl-stroke trial. SF, HR, BLa and RPE showed higher values in the swimming pool compared with the swimming flume, while SL, SI and Pe showed lower values. SL, SI and $v$ were the variables that increased significantly thanks to wearing wetsuit, no statistical differences were found in the rest of variables.

The participants in the study wore a complete wetsuit during the specific trials to obtain the maximum advantage. It was justified by the study developed by Trappe et al. (1996) that compared three types of wetsuit (complete, long and short) and they found significant reduction in oxygen uptake, minute ventilation and heart rate wearing the complete wetsuit.

Our results showed a reduction in the final $400 \mathrm{~m}$ crawl-stroke time equal to $20.08 \mathrm{~s}$ (5.77\%). This improvement was consistent with the obtained by Chatard et al. (1995), $6 \%$, L. Cordain \& Kopriva (1991) 5\%, both studies in 400m crawl-stroke. Additionally, Parsons \& Day (1986), found an improvement of 7\% with the use of wetsuit in 30 min swim.

Physiological variables as HR and BLa showed specific behavior on each experimental condition. HR was no significantly higher while wearing wetsuit and BLa no significantly lower in swimming pool and swimming flume. The expected additional buoyancy and reduced active drag provided by the wetsuit, it allowed the performance improvement, while the physiological variables were kept almost constant. These physiological variables were reduced significantly between swimming pool and swimming flume. Swimming in the flume at similar velocity than swimming pool reduced the HR (about a 5\%) and BLa (about a 29\%). These differences can be explained by the "pace effect" or constant velocity provided by the swimming flume that induced better energy balance between the beginning and the end of the effort and the turning effect that could be specifically added on triathletes. Furthermore, the specific environment conditions of the swimming flume, where the water impelled had a narrow displacement can modify these results. These results are similar in the RPE, which is reduced about a $25 \%$. They can be explained in the same way.

Technical variables had different results depending of its link with the mean velocity established after the swimming pool trials. Mean velocity was increased about a 5\% thanks to the use of the wetsuit and these results were applied in the swimming flume trials. SF was similar comparing swimsuit and wetsuit conditions and it was decreased 
about a $17 \%$ in the swimming flume. SL increased thanks to the use of wetsuit in both swimming pool conditions (about a 6\%) and similarly affected by the change of the swimming pool that increased the SL about a 30\%. Similar results than SL were found in the SI, while the Pe was increased about a net $11 \%$ in the swimming flume, without differences due to the suit effect.

Related to the physiological variables our results of HR agreed with Trappe et al., (1996) who found a decrement with the use of wetsuit in the swimming flume. Nevertheless, we found the HR higher in with wetsuit in the swimming pool. The temperature could influence it during a submaximal effort with wetsuit, which increased the corporal temperature and produced a high HR. In contrast, the situation in the swimming flume with wetsuit, the HR is reduced because the velocity is constant and the turn effect is not accounted.

The use of wetsuit reduces the time in $400 \mathrm{~m}$ and, as a consequence, the effort is lessened. It can be observed in the BLa which was reduced in the wetsuit conditions as happened in the study of De Lucas et al., (2000) where the blood lactate concentration in 1500 swim was less with the use of wetsuit. However, the study of Chatard et al., (1995) in swimmers in 400m trial the BLa was lower swimming with wetsuit but it was not statistically significant. Tomikawa \& Nomura (2009) found significant differences in the BLa with wetsuit in a swimming flume, but higher values were found.

The RPE was similar in the situations with swimsuit and wetsuit in the $25 \mathrm{~m}$ pool and between swimsuit and wetsuit in the swimming flume, but Trappe et al., (1996) found significant differences with and without wetsuit in the swimming flume with swimmers. The differences in the swimming flume design and size can explain these differences. Nevertheless, Tomikawa et al, (2008) didn't find significant evidences of lower BLa and RPE with wetsuit in the swimming flume. A reason may be the intensity of the effort, which was $60 \%$ and $80 \%$ of $\mathrm{VO}_{2 \max }$.

Related to the technical variables, SF was increased with wetsuit in the swimming pool as Perrier \& Monteil (2004) showed but in effort of 1500m and Chatard et al. (1995) in $400 \mathrm{~m}$ trials in triathletes. In the same distance Tomikawa \& Nomura (2009) found an increase of SF with wetsuit. In our study, in the swimming flume the SR was reduced in both swimsuit and wetsuit but with the same value $(0.52 \mathrm{~Hz})$. The same author found an increase in SR with wetsuit respect to swimsuit in the swimming flume $(0.55 \mathrm{~Hz}, 0.53 \mathrm{~Hz}$ respectively) (Tomikawa et al., 2008). Unlike occurred with the SL, which was increased in the swimming pool with wetsuit versus swimsuit $(P<0.05)$ and in the swimming flume with wetsuit versus swimsuit $(P<0.001)$. The same happened in the study of Trappe et al. (1995) in effort of 30 min but not in Perrier \& Monteil (2001) where with full wet suit the SL didn't increased. Meanwhile, Nicolau et al., (2001) didn't find significant differences in those two types of wetsuit in stroke length. However, Tomikawa et al, (2008) didn't find significant evidences of a higher SL with wetsuit in the swimming flume. But finally, one year later, the same author found a 
higher SL with wetsuit in a $400 \mathrm{~m}$ test in the swimming flume $(P<0.01)$ (Tomikawa \& Nomura, 2009), in accordance with our results.

The energy expenditure was studied with middle distance swimmers, and their results showed how the stroke index was the best predictor of $\mathrm{VO}_{2 \max }$ for trained swimmers as the lean body weight ( $r=0.97)$ (Costill et al., 1985). Even the stroke length was the best single predictor of performance in 400 yards swim $(\approx 400 \mathrm{~m} ; 365.8 \mathrm{~m})(r=0.88)$. In the present study, the propelling efficiency was related to the stroke length $(r=0.74)$ in the experimental condition: wetsuit in the swimming flume.

Pe values obtained in our study were similar to other authors (Seifert et al., 2015; Hubb M Toussaint et al., 1988; H. M. Toussaint et al., 1989; Zamparo et al., 2005).

\section{Limitations}

Previous experience in the use of the wetsuit should be introduced as co-variable. A standardized model of wetsuit should be dressed to all the subjects of the study. A sample of subjects with similar experience and age-group should be recommended.

Future study directions are oriented to the analysis of more metabolic and biomechanical variables as $\mathrm{VO}_{2}$ and the index of coordination, comparing the results with performance measures in open water. 


\section{CONSLUSIONS}

The use of the wetsuit has a strong influence on $400 \mathrm{~m}$ performance, thanks to small increments of stroke frequency and stroke length, confirmed by the changes in the stroke index.

All the variables studied physiological and technical are modified by the use of swimming flume at similar velocities than swimming pool. This effect can be summarized by a $10 \%$ of increment of the propelling efficiency.

Similar values have been observed between swimsuit and wetsuit in both swimming pool conditions.

This conclusions recommends a more detailed analysis of the effect of the swimming flume on swimming physiology and technique, and do not mix the results in this environment with the obtained in the swimming pool.

\section{ACKNOLEDGEMENTS}

The author would like to thank the participants for their cooperation, the Research Group "Physical Activity and Sports in Aquatic Environment - CTS 527" for their support with material and register equipment to develop the study, the Project funded by MINISTERIO DE ECONOMIA Y COMPETITIVIDAD, Programa Estatal de Fomento de la Investigación Científica y Técnica de Excelencia (I+D+i), DEP2014-59707-P. SWIM: Specific Water Innovative Measurements, applied to the development of International Swimmers in Short Swimming Events (50 and 100m) and Ministry of Science and Innovation of Spain which funded partially these experiments and finally the Collaboration Scholarship form The Ministry of Education, Spain. 


\section{REFERENCES}

Barbosa, T. M., Bragada, J. A., Reis, V. M., Marinho, D. A., Carvalho, C., \& Silva, A. J. (2010). Energetics and biomechanics as determining factors of swimming performance: updating the state of the art. Journal of Science and Medicine in Sport, 13(2), 262-269.

Borg, G. (1998). Borg's perceived exertion and pain scales: Human kinetics.

Costill, D., Kovaleski, J., Porter, D., Kirwan, J., Fielding, R., \& King, D. (1985). Energy expenditure during front crawl swimming: predicting success in middledistance events. Int J Sports Med, 6(5), 266-270.

Craig, A. B., \& Pendergast, D. R. (1979). Relationships of stroke rate, distance per stroke, and velocity in competitive swimming. Med Sci Sports Exerc, 11(3), 278-283.

Chatard, J. C., \& Millet, G. (1996). Effects of wetsuit use in swimming events Practical recommendations. Sports Medicine, 22(2), 70-75.

Chatard, J. C., Senegas, X., Selles, M., Dreanot, P., \& Geyssant, A. (1995). Wet suit effect - A comparison between competiive swimmers and triathletes. Medicine and Science in Sports and Exercise, 27(4), 580-586.

De Koning, J. J., Foster, C., Bakkum, A., Kloppenburg, S., Thiel, C., Joseph, T., . . . Porcari, J. P. (2011). Regulation of pacing strategy during athletic competition. Plos One, 6(1), e15863.

De Lucas, R. D., Balikian, P., Neiva, C. M., Greco, C. C., \& Denadai, B. S. (2000). The effects of wet suits on physiological and biomechanical indices during swimming. Journal of Science and Medicine in Sport, 3(1), 1-8.

De Rose, E., \& Guimaraes, A. (1980). A model for optimization of somato-type in young athletes Kinanthropometry II., de Ostyn, M., G., Simons. J. Baltimore.

Faulkner, J. A. (1968). Physiology of swimming and diving. Exercise physiology(part II).

FINA Points Scoring, Short Course, (2015).

Hue, O., Benavente, H., \& Chollet, D. (2003). The effect of wet suit use by triathletes: an analysis of the different phases of arm movement. Journal of Sports Sciences, 21(12), 1025-1030. doi: 10.1080/0264041031000140419

Hutteau, M., Beitucci, W., \& Lodini, A. (2007). Effect of using a complete wetsuit and a tri function on swimming speed and amplitude in triathlon. Science \& Sports, 22(1), 60-62. doi: 10.1016/j.scispo.2006.09.009

Jean-St-Michel E., Cedric Manlhiot, Jing Li, Michael Tropak, Marie M. Michelsen, Michael R. Schmidt, . . . Redington, A. N. (2011). Remote Preconditioning Improves Maximal Performance in Highly Trained Athletes. Medicine \& Science in Sports \& Exercise, 43(7), 1280-1286. doi: DOI: 10.1249/MSS.0b013e318206845d

L. Cordain, \& Kopriva, R. (1991). Wetsuits, body density and swimming performance. Sports Medicine, 25(1).

Martin, R. B., Yeater, R. A., \& White, M. K. (1981). A simple analytical model for the crawl stroke. Journal of biomechanics, 14(8), 539-548.

McLean, S. P., Palmer, D., Ice, G., Truijens, M., \& Smith, J. C. (2010). Oxygen uptake response to stroke rate manipulation in freestyle swimming. Med Sci Sports Exerc, 42(10), 1909-1913. doi: 10.1249/MSS.0b013e3181d9ee87

Nicolaou, K. D., Kozusko, J. M., \& , \& Bishop, P. A. (2001). The Effect of Wetsuits on Swim Performance. Journal of Swimming Research, 15. 
Parsons, L., \& Day, S. (1986). Do wet suits affect swimming speed? British journal of sports medicine, 20(3), 129-131.

Perrier, D., \& Monteil, K. (2004). Triathlon wet suit and technical parameters at the start and end of a 1500-m swim. Journal of Applied Biomechanics, 20(1), 3-13.

Perrier, D., \& Monteil, K. M. (2001). Wetsuits and performance: Influence of technical abilities. Journal of Human Movement Studies, 41(3), 191-207.

Sanchez C., Zabala M. (2015). Course of Corporal Composition. Ergosport. Consejo Superior de Deportes, Licencias y Clubes Federados, 2010-2015.

Seifert, L., Schnitzler, C., Bideault, G., Alberty, M., Chollet, D., \& Toussaint, H. M. (2015). Relationships between coordination, active drag and propelling efficiency in crawl. Human movement science, 39, 55-64.

Tomikawa, M., \& Nomura, T. (2009). Relationships between swim performance, maximal oxygen uptake and peak power output when wearing a wetsuit. $J$ Sci Med Sport, 12(2), 317-322. doi: 10.1016/j.jsams.2007.10.009

Tomikawa, M., Shimoyama, Y., \& Nomura, T. (2008). Factors related to the advantageous effects of wearing a wetsuit during swimming at different submaximal velocity in triathletes. J Sci Med Sport, 11(4), 417-423. doi: 10.1016/j.jsams.2007.02.005

Toussaint, H. M. (1990). Differences in propelling efficiency between competitive and triathlon swimmers Medicine and Science in Sports and Exercise, 22(3), 409415.

Toussaint, H. M., Beelen, A., Rodenburg, A., Sargeant, A. J., de Groot, G., Hollander, A. P., \& van Ingen Schenau, G. J. (1988). Propelling efficiency of front-crawl swimming. Journal of Applied Physiology, 65(6), 2506-2512.

Toussaint, H. M., Bruinink, L., Coster, R., Delooze, M., Vanrossem, B., Vanveenen, R., \& Degroot, G. (1989). Effect of a triathlon wet suit on drag during swimming. Medicine and Science in Sports and Exercise, 21(3), 325-328.

Trappe, T. A., Pease, D. L., Trappe, S. W., Troup, J. P., \& Burke, E. R. (1996). Physiological responses to swimming while wearing a wet suit. International Journal of Sports Medicine, 17(2), 111-114. doi: 10.1055/s-2007-972817

Trappe, T. A., Starling, R. D., Jozsi, A. C., Goodpaster, B. H., Trappe, S. W., Nomura, T., . . . Costill, D. L. (1995). Thermal responses to swimming in three water temperatures: influence of a wet suit. Medicine and Science in Sports and Exercise, 27(7), 1014-1021.

Ulsamer, S., Rust, C. A., Rosemann, T., Lepers, R., \& Knechtle, B. (2014). Swimming performances in long distance open-water events with and without wetsuit. BMC Sports Sci Med Rehabil, 6(20). doi: 10.1186/2052-1847-6-20

Zamparo, P., Pendergast, D., Mollendorf, J., Termin, A., \& Minetti, A. (2005). An energy balance of front crawl. European Journal of Applied Physiology, 94(1-2), 134-144. 
